\title{
DISCIPLINE-BASED EDUCATION RESEARCH (DBER) - WHAT IS IT, AND WHY SHOULD ENGINEERING EDUCATION RESEARCH SCHOLARS BE TALKING ABOUT IT MORE?
}

\author{
Robyn Paul and Robert Brennan \\ Schulich School of Engineering, University of Calgary \\ rmpaul@ucalgary.ca
}

\begin{abstract}
Engineering Education Research (EER) is a growing field in Canada. However the interdisciplinary nature of our field means we frequently face challenges, often in the form of deficits: funding, support from colleagues, sufficient interdisciplinary expertise, and recruitment of and support for post-graduate students. In order to continue growing the EER field, we need to provide academic scholars and students with the necessary interdisciplinary support systems. This paper provides an overview of the field of Discipline-Based Education Research (DBER) and makes recommendations on how EER scholars can more intentionally engage. Specifically, through knowledge sharing, communities of practices, and collaborative infrastructures and systems.
\end{abstract}

Keywords: Discipline-Based Education Research, DBER, Engineering Education Research, Interdisciplinary research

\section{INTRODUCTION}

Engineering Education Research (EER) is a growing field in Canada. However the interdisciplinary nature of our field means we frequently face challenges, often in the form of deficits: funding, support from colleagues, sufficient interdisciplinary expertise, and recruitment of and support for post-graduate students [1]. In order to continue growing the EER field, we need to provide academic scholars and students with the necessary interdisciplinary support systems.

Discipline-based education research (DBER) is defined as research that aims to understand teaching and learning in a discipline while considering the priorities, viewpoints, knowledge, and practices of that discipline. High-quality DBER, brings in expertise from the specific discipline including the challenges of education in that discipline, along with general expertise from the science of teaching and learning [2]. From this definition, Engineering Education Research (EER), evidently is a subfield within the larger field of DBER.
This paper provides an overview of DBER and outlines motivation on the importance of EER scholars to become intentionally engaged in the field of DBER. I then recommend an approach to Engineering Education Research that will help to ensure we integrate available knowledge from other disciplines into our research.

\section{BACKGROUND}

\subsection{Discipline-Based Education Research (DBER)}

Each discipline has a unique trajectory of developments in DBER, this paper mostly focuses on STEM disciplines. Quality of postsecondary education became a common discussion in the early 1900s, but it wasn't until the 1970s through 1990s that true DBER emerged looking at understanding student learning and improving the quality of education [2]. Physics education was the first to have relatively widespread systematic educational research activities and programs to support the research starting in the 1970s (such as $\mathrm{PhD}$ programs and institutional physics education research grants). Although, Engineering has perhaps been talking about education for the longest, with the American Society for Engineering Education being founded in 1893, the research-focused activities really didn't expand until outcomes-based education was implemented in 2000 in the US [3] and 2010 in Canada [4]. Most other STEM disciplines such as chemistry, biology, astronomy, and computer science each have their own DBER trajectories and are at different stages of development.

In 2012, the National Research Council (NRC) recognized that DBER was emerging as a "vital area of scholarship" [2], and they put together a comprehensive report on the status of DBER, the biggest contributions that have come from DBER, and future directions of DBER. The report outlines the goals of DBER to be the following:

- understand how people learn the concepts, practices, and ways of thinking of science and engineering;

- understand the nature and development of expertise in a discipline; 
- help identify and measure appropriate learning objectives and instructional approaches that advance students toward those objectives;

- contribute to the knowledge base in a way that can guide the translation of DBER findings to classroom practice; and

- identify approaches to make science and engineering education broad and inclusive [2].

Although each discipline has their own branch of DBER, there is some research that shows the most effective strategies to improve student learning are independent of the discipline [5]. Often, the same research will be done many times over in order to ensure applicability across disciplines. Although perhaps redundant, this can help make the evidence of a particular teaching practice more accessible to a wider audience, and can ensure that educational research is most relevant to the discipline [6].

It is important to also understand that learning disciplinary content is a socialization process. Students must learn the "prevailing ways of thinking, feeling, and behaving" [7] of their discipline. The underlying attributes and a culture of a discipline varies, and thus the socialization in an integral aspect. DBER scholars are therefore uniquely positioned to integrate their important disciplinary contexts into innovative teaching and learning practices.

\subsubsection{Current Challenges in DBER}

One of the biggest challenges observed by the NRC and other authors [5], [8] is that although there are many significant findings in DBER, there has been limited adoption of these changes into practice. Changing faculty behaviour is a complex process that requires more than evidence-based facts. One needs to have the skill (knowledge), the will (motivation), and the thrill (reward) [7]. This is exemplified by the fact that often those who attend teaching workshops are already actively engaged in improving their teaching practices; they have the will and are looking to develop the skill.

A frequently cited barrier to implementation is access to active-learning style classrooms. However, one study found that in an active-learning style classroom, $55 \%$ of people still taught using traditional didactic, $27 \%$ used interactive methods, and only $18 \%$ used student-centered methods [8]. This shows that the classroom itself is not enough along to promote student-centered teaching. Perhaps the value placed on teaching and its impact on classroom practices needs to be investigated.

There is a perception in academia that technical research is more important than teaching and teaching research. This is evidenced by research that shows "the more time faculty spend in the classroom teaching the lower the average salary" [5]. Many believe teachingstream faculty members are hired simply to take on higher teaching loads so research-stream faculty members have more time for their research. And yet, on top of their teaching load, they are often also expected to provide teaching consultations to their colleagues and engage in DBER or SoTL research.

Beyond the challenges mentioned above, there are other barriers to the advancement of DBER outlined by the NRC and others [2], [5], [8], [9]. Firstly, it is essential to provide training in conducting educational research about how people think and learn in a discipline. Specifically, this requires the development of formal DBER graduate programs and DBER postdoctoral positions. Additionally, infrastructure and systems need to be built including conference sections, research journals, other publication venues, research centres, and policy statements from professional organizations. Lastly and most importantly, DBER research needs to be recognized and funded by institutions and funding agencies locally and nationally.

\subsubsection{Scholarship of Teaching and Learning (SoTL)}

We cannot discuss DBER, without discussing the Scholarship of Teaching and Learning (SoTL). Many scholars debate the differences and overlaps of DBER and SoTL [10]. Simply put, DBER is research-focused seeking "to increase the theoretical and empirical knowledge base of teaching and learning in a discipline" whereas SoTL is practice-focused seeking "to improve the effectiveness of individual teachers and the use of evidence-based curricula or pedagogy" [10].

Due to the research vs. practice differences, there can be a perception that SoTL is less than DBER [7]. However, the two are equally critical to advancing our understanding and implementation of effective teaching and learning within disciplines. There is value for both research and practice, and thus we must avoid comparison and "intellectual snobbery" [10]. Within Canadian engineering education specifically, I was involved in a study looking at the type of research being published at CEEA from 2005 to 2017 [4]. Discussion following the presentation of these results at CEEA 2018 emphasized the importance the community values on both empirical research (DBER) and sharing of experiences through practice (SoTL).

For the purposes of this paper, I will focus on DBER, although personally the distinction of the two is less important than the advancement of the field towards the goal of improving student learning.

\subsection{Engineering Education Research (EER)}

Engineering Education Research (EER), is a sub-field within the larger field of DBER, and is a growing area of scholarship around the world. Most technical engineering conferences now have an educational track, and the annual conference of the American Society of Engineering Education (ASEE) is attended by over 6,000 people. 
The growth of the EER field saw a notable increase with the introduction of outcomes-based education. As mentioned previously, outcomes-based education has become increasingly common across engineering accreditation bodies worldwide since its first major introduction in 2000 in the United States [3]. In Canada, a list of 12 graduate attributes became part of the engineering accreditation process in 2010 .

The rise of outcomes-based education has led to significant increases in the growth of engineering education research [4]. For example, in 2010, the year the $\mathrm{CEAB}$ graduate attributes became a requirement, the number of papers almost doubled at the CEEA Annual Conference. There were under 50 papers in 2009 to upwards of 90 papers in 2010. In its most recent year, the 2018 conference had over 140 papers published, with a significant increase over the years in those focused on educational research [4]. It is evident that due to outcomesbased education requirements, many engineering professors are now reflecting on their teaching and engaging in national and international discussions on best practices and innovative pedagogies in engineering classrooms.

With the growth of EER, particularly in the last two decades, there have been efforts to standardize and solidify appropriate methodologies [11], [12], [13]. Specifically, there has been a movement recently to emphasize the value of qualitative educational research in engineering education [14].

\section{MOTIVATIONS}

If you are involved in EER research, while reading section 2.1.1 Current Challenges in DBER, you may have felt similarities with challenges you have personally experienced. Many of the challenges outlined by the NRC I have felt myself, and I have heard my colleagues discuss. Through these parallels, it is evident that EER can learn from work being done to advance DBER.

Although you may already be aware of DBER and its importance, the idea of this paper came from conversations with colleagues and from my own journey. When I first started researching engineering education, I only ever looked into EER literature. As my knowledge grew in the field, I realized I was missing out on a huge wealth of knowledge and on opportunities to collaborate with individuals across my own campus doing DBER research. I present three motivations for writing this paper, and arguments as to why I believe EER scholars should intentionally integrate with the field of DBER.

\subsection{Tap into the wealth of DBER knowledge}

Firstly, the purpose of EER is to improve student learning experiences. By engaging in DBER, we can learn from what has already be done in other disciplines such as chemistry, physics, and math. We can then consider how the learnings from these disciplines apply to engineering. To highlight a few recent examples, here are some paper publication in DBER journals that could be relevant to EER scholars:

- "Flat Earth theory: an exercise in critical thinking" (Physics Education journal) [15]

- "Using high speed smartphone cameras and video analysis techniques to teach mechanical wave physics" (Physics Education journal) [16]

- "Solving Equations: Exploring Instructional Exchanges as Lenses to Understand Teaching and Its Resistance to Reform" (Journal for Research in Mathematics Education) [17]

- "Machine Learning for Fluid Property Correlations: Classroom Examples with MATLAB" (Journal of Chemical Education) [18]

- "I Wanna Just Google It and Find the Answer': Student Information Searching in a Problem-Based Inorganic Chemistry Laboratory Experiment" (Journal of Chemical Education) [19]

These are just a few highlighted examples of research happening in other disciplines with findings that could be insightful and applicable to engineering.

\subsection{Improve perception of EER as research field}

Secondly, as discussed previously, scholars in EER can be perceived to not be doing "real" research. They often receive resistance from their colleagues, leaving them feeling silo-ed. Expanding our network of peers, particularly within our own institution, to include our DBER colleagues will allow us to foster a community of practice. This will increase our support systems and opportunities for in-house collaborations. Through a large research network, the perceived value of DBER as a legitimate and validated field of research would increase. Additionally, interdisciplinary collaborations across DBER may provide particularly good momentum for translation of research results into practice [9].

\subsection{Build EER infrastructures and systems}

Lastly, to advance EER we need a robust research infrastructure that considers sustained funding models, training, venues for peer-reviewed publications, and opportunities for recognition [2]. Additionally, post graduate and postdoctoral research are essential mechanisms for high quality research output. By working together with the lager DBER network, we may have the necessary mass to move forward on some of these infrastructures and systems within our institutions, and at a national scale.

Additionally, building communities of practice within our own institutions will provide DBER scholars with the necessary support system of colleagues, that is sometimes lacking within our own department [10]. Intentionally 
building these collaborative systems for DBER researchers across an institution will allow for sharing of resources and expertise to help further each individual field.

\section{RECOMMENDED APPROACH FOR EER RESEARCH}

As we approach research in engineering education, we should ensure we are incorporating knowledge from DBER fields. Additionally, research should be underlined in the foundations from the learning sciences. Figure 1 below provides a visual description of the recommended research approach.

For example, perhaps we are considering a research question looking at the implementation of critical thinking in a first-year engineering statics classroom. Firstly, we should explore critical thinking literature from education and/or psychology. What does critical thinking mean, and what are some key understandings of critical thinking from the learning sciences? Secondly, we should look at what others in DBER have done. For example, the physics article mentioned above "Flat Earth theory: an exercise in critical thinking" [15] may provide interesting insights. Lastly, we should look into what others in engineering have done, and how the discipline of engineering might specifically need to consider critical thinking within our classrooms. The order of these steps is less important than ensuring we have touched on each aspect.

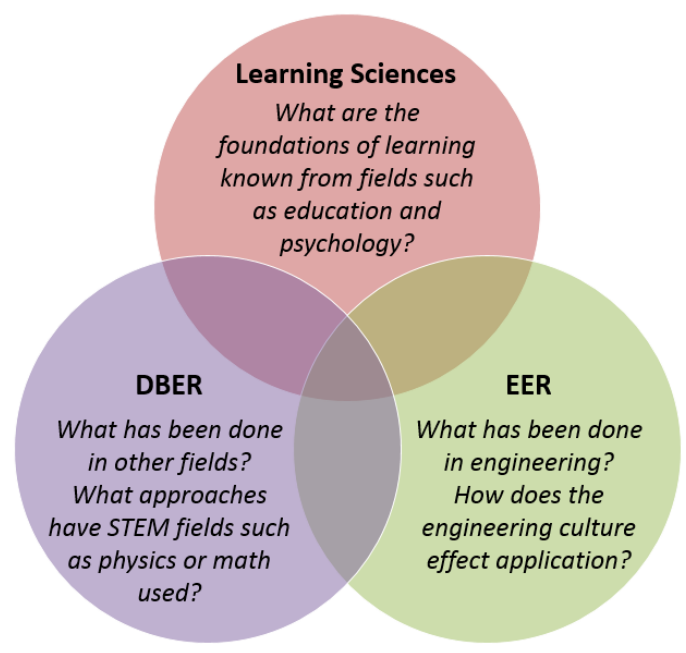

Fig. 1. Recommended approach for EER research.

\section{CONCLUSIONS}

There are many challenges that come with the growth of Engineering Education Research. Similar fields under the umbrella of Discipline-Based Education Research have faced similar challenges. This paper suggests that interdisciplinary collaboration would provide support structures and systems to move the DBER fields forward.
Specifically, through knowledge sharing, communities of practices, and collaborative infrastructures and systems.

It is important to acknowledge this paper focused on a high-level discussion of DBER and EER. The importance of educational research methodologies within EER has not been discussed. This is a whole other crucially imperative topic for conducting quality EER work that I recommend looking into [11], [12], [13], [14], [20].

\section{References}

[1] J. Seniuk Cicek, P. Sheridan, L. Kuley, and R. Paul, "Through 'Collaborative Autoethnography': Researchers Explore Their Role as Participants in Characterizing the Identities of Engineering Education Graduate Students in Canada," ASEE Annual Conference \& Exposition, 2017.

[2] National Research Council. Discipline-Based Education Research: Understanding and Improving Learning in Undergraduate Science and Engineering. Washington, DC: The National Academies Press, 2012.

[3] J. E. Froyd, P. C. Wankat, and K. A. Smith. "Five major shifts in 100 years of engineering education," in Proceedings of the IEEE, vol. 100, no. Special Centennial Issue, pp. 1344-1360, 2012.

[4] R. Brennan, R. Hugo, K. Johnston, N. Nelson, R. Paul, and M. Sullivan, "A systematic review of Canadian Engineering Education Research 2004-2017," in Proceedings of the Canadian Engineering Education Association (CEEA), 2018.

[5] J. Fairweather. "Linking evidence and promising practices in science, technology, engineering, and mathematics (STEM) undergraduate education." Board of Science Education, National Research Council, The National Academies, Washington, DC, 2008.

[6] C. Henderson et al. "Towards the STEM DBER alliance: Why we need a discipline-based STEM education research community," International Journal of STEM Education, vol. 4 , no. 14, 2017.

[7] B. Coppola and J. Krajcik. "Discipline-centered postsecondary science education research: Understanding university level science learning," Journal of Research in Science Teaching, vol. 50, no. 6, pp. 627-638, 2013.

[8] M. Stains et al. "Anatomy of STEM teaching in North American universities." Science, vol. 359, no. 6383, pp. 1468-1470, 2018.

[9] B. P. Coppola and J. S. Krajcik. "Discipline-centered postsecondary science education research: Distinctive targets, challenges and opportunities." Journal of Research in Science Teaching, vol. 51, no. 6, pp. 679-693, 2014.

[10] T. F. Shipley "Transdisciplinary science education research and practice: Opportunities for GER in a developing STEM discipline-based education research alliance (DBERA)." Journal of Geoscience Education, vol. 65, no. 4, pp. 354-362, 2017. 
[11] M. Borrego, M. J. Foster, and J. E. Froyd. "Systematic literature reviews in engineering education and other developing interdisciplinary fields." Journal of Engineering Education, vol. 103, no. 1, pp. 45-76, 2014.

[12] J. M. Case and G. Light. "Emerging research methodologies in engineering education research." Journal of Engineering Education vol. 100, no. 1, pp. 186-210, 2011.

[13] C. J. Finelli, M. Borrego, and G. Rasoulifar. "Development of a taxonomy of keywords for engineering education research." IEEE Transactions on Education, vol. 58, no. 4, pp. 219-241, 2015.

[14] C. Baillie, and E. P. Douglas. "Confusions and conventions: Qualitative research in engineering education." Journal of Engineering Education, vol. 103, no. 1, 2014.

[15] B. Leontýna et al. "Flat Earth theory: an exercise in critical thinking." Physics Education, vol. 53, no. 4, 2018.

[16] J. Bonato et al. "Using high speed smartphone cameras and video analysis techniques to teach mechanical wave physics." Physics Education, vol. 52, no. 4, 2017.
[17] O. Buchbinder, D. I. Chazan, and M. Capozzoli. "Solving Equations: Exploring Instructional Exchanges as Lenses to Understand Teaching and Its Resistance to Reform." Journal for Research in Mathematics Education, vol. 50, no. 1, pp. 51-83, 2019.

[18] L. Joss and E. A. Müller. "Machine Learning for Fluid Property Correlations: Classroom Examples with MATLAB." Journal of Chemical Education, vol. 96, no. 4, pp. 697-703, 2019.

[19] G. V. Shultz and J. M. Zemke. "'I Wanna Just Google It and Find the Answer": Student Information Searching in a Problem-Based Inorganic Chemistry Laboratory Experiment." Journal of Chemical Education, vol. 96, no. 4, pp. 618-628, 2019.

[20] A-K. Carstensen, and J. Bernhard. "Design science research-a powerful tool for improving methods in engineering education research." European Journal of Engineering Education, vol. 44, no. 1-2, pp. 85-102, 2019. 